\title{
Costless Discrimination and Unequal Achievements in an Experimental Tournament
}

\author{
Antonio Filippin and Francesco Guala \\ Department of Economics, Management and Quantitative Methods \\ Università degli Studi di Milano ${ }^{\dagger}$ \\ antonio.filippin@unimi.it; francesco.guala@unimi.it
}

\begin{abstract}
We investigate the emergence of discrimination in an experiment where individuals affiliated to different groups compete for a monetary prize, submitting independent bids to an auctioneer. The auctioneer receives perfect information about the bids (there is no statistical discrimination), and she has no monetary incentive to favor the members of her own group (the bidders are symmetric). We observe nonetheless some discrimination by auctioneers, who tend to assign the prize more frequently to a member of their own group when two or more players put forward the highest bid. Out-group bidders react to this bias and reduce significantly their bids, causing an average decay of their earnings throughout the game, with cumulative effects that generate unequal outcomes. Because the initial bias is costless, such mechanism can survive even in a competitive market, providing a rationale for the long-run persistence of discrimination.
\end{abstract}

Keywords: discrimination; tournament; groups; experiment.

JEL codes: J71, D44, C9

\footnotetext{
$\dagger$ Research for this paper was financed by a PUR grant and a "Rientro dei Cervelli" scholarship. We are grateful to Manuela Raimondi and the experimental laboratory of the University of Parma for logistic support. We would like to thank Olivier Armantier, Anat Bracha, Jordi Brandts, John Kagel, and two anonymous referees for helpful suggestions. We also thank participants at the "6th Nordic Conference on Behavioral and Experimental Economics" (Lund), the conference "Experimental Methods and Economic Modelling" (Capua), the 2011 meetings of the ESA (Chicago) and AIEL (Milan), and a seminar held at the University of Milan for their comments. The usual disclaimers apply.
} 


\section{Introduction: social groups and discrimination}

Discrimination is a despicable phenomenon that affects in different forms various aspects of social life. It may concern gender, race, social class, geographic origins, ethnicity, age, and several other social categories (Altonji and Blank 1999, Rodgers 2006). For this reason, discrimination has been studied by different disciplines using different methods, and different theories have been proposed to explain its emergence and persistence through time. In this paper we focus in particular on the effect of group identity on discrimination, in the context of an experimental tournament where bidders invest resources to obtain a prize awarded by an auctioneer who observes their exact bids. Bidders are entirely symmetric, except that some of them belong to the same group as the auctioneer. We investigate whether mere categorization is sufficient to induce discriminatory beliefs, and to generate unequal achievements among perfectly symmetric, perfectly informed economic agents.

Several theories posit a link between group identity and discrimination. From an evolutionary perspective, Homo Sapiens may have evolved a propensity to cooperate with the members of her own family or tribe, while competition for territory and resources may have made suspicion and hostility advantageous in the context of inter-group behavior. The propensity to discriminate against members of other groups, then, may be a (maladaptive) trait selected in an ancestral environment that differed radically from the large multicultural societies we currently live in. ${ }^{1}$ The existence of such a propensity is confirmed by a large number of studies conducted by social and cognitive scientists. In a famous field experiment with middle-class teenagers, Muzafer Sherif showed that the mere creation of group identities in the context of a peaceful summer camp increased significantly the level of competition and aggressiveness (to the point that the experiment had to be suspended - see Sherif et al. 1961). Henri Tajfel and his co-authors pursued a similar line of research using the so-called "minimal group paradigm", an experimental setting where subjects' behavior is manipulated using artificial groups based on arbitrary criteria and meaningless labels (Tajfel et al. 1971, Tajfel 1982). Again, it turns out that individuals become more cooperative, altruistic and caring towards the members of their own group than the members of other groups. From an economic point of view, it is noteworthy that group members are willing to pay a cost to increase inter-group differences in earnings or achievements (they are inefficiently spiteful towards out-group members, in other words).

\footnotetext{
${ }^{1}$ Cf. e.g. Richerson and Boyd (2001), Bernhard, Fehr and Fischbacher (2006), Choi and Bowles (2007), Efferson, Lalive and Fehr (2008), Bowles and Gintis (2011).
} 
With the development of experimental economics, some of the concepts and techniques developed by psychologists have been transferred in the economic literature. Variants of Tajfel's minimal group paradigm for example have been used to study cooperation and social preferences in simple strategic games. ${ }^{2}$ Other studies have used affiliation to real groups to explore a range of issues that go from gender wage-gaps to the effect of ethnic identity, race, and religion in economic contexts. ${ }^{3}$ This empirical work was partly stimulated by a budding theoretical literature that aims at incorporating group identity into economic modelling (e.g. Sugden 2000, Bacharach 2006, Akerlof and Kranton 2010).

From a theoretical point of view, group identity may influence the attitude of the decisionmaker roughly in two ways: by changing her beliefs about the characteristics of other individuals (for example: "she is Japanese, therefore she is a cooperative, hard-working person"); or by changing her affective orientation ("I like her, because she is Japanese"). These two mechanisms have rather different implications, which economists working on discrimination have been exploring for many years.

In a seminal series of papers Gary Becker (1957) proposed an explanation of discrimination in the labor market that is driven entirely by the preferences of employers, customers or co-workers. While the generality of this model makes it applicable to a number of real-world cases (sex, religion, race, etc.) it also raises the puzzle of the persistence of discrimination in a competitive environment. If discrimination implies a competitive disadvantage, it should be wiped away by market pressure in the long run, in spite of abundant evidence to the contrary. ${ }^{4}$ So partly out of dissatisfaction with preference-based models, economists started to devise in the 1970s theories that can explain the existence of discrimination equilibria in competitive markets. Phelps (1972) and Arrow (1973) modelled discrimination as a self-fulfilling prophecy in two seminal papers that started the branch of so-called theories of "statistical discrimination" (for a survey see Fang and Moro 2011). The Arrow approach shows that employers' beliefs about the existence of different characteristics

\footnotetext{
${ }^{2}$ See e.g. Yamagishi, Jin and Kiyonari (1999), Eckel and Grossman (2005), Charness, Rigotti and Rustichini (2007), Fehr, Bernhard and Rockenbach (2008), Chen and Li (2009), Güth, Ploner and Regner (2009), Hargreaves Heap and Zizzo (2009), Zizzo (2011).

${ }^{3}$ See for example Freshtman and Gneezy (2001), Freshtman, Gneezy and Verboven (2005), Ruffle and Sosis (2006), Benjamin, Choi and Strickland (2010), Goette et al. (2010).

${ }^{4}$ Darity and Mason (1998) and Altonji and Blank (1999) survey the empirical evidence on discrimination in the labor market. Notice that in some special cases discrimination and market competition may co-exist: if customers have discriminatory tastes (for example, if they prefer to be served by the members of a certain social group) competition should induce firms to implement discriminatory hiring policies. But the general point holds for all those markets where customers ignore or are indifferent about the social identity of the producer.
} 
between groups of workers can be self-fulfilling in equilibrium. The mechanism is the following: an a priori unobservable characteristic of workers (e.g. effort) is endogenously affected by employer's beliefs (e.g. via lower wages or via worse job assignments), leading to a suboptimal choice of effort that determines an outcome consistent with the beliefs of the employer.

Attempts to observe statistical discrimination in the laboratory however have fared rather poorly (e.g. Davis 1987, Feltovich and Papageorgiou 2004, Fryer, Goeree and Holt 2005, Filippin 2008; see also the survey of Anderson, Fryer and Holt 2006). A recent unpublished paper by de Haan, Offerman and Sloof (2011) is the only exception so far: de Haan and co-authors report an experiment where symmetric workers labelled with arbitrary colors ("green" and "purple") compete for a job. Employers observe noisy investment signals and discover the real quality of workers only after they have made their hiring decisions. ${ }^{5}$ Although multiple equilibria are possible, the "fair" equilibrium (where employers treat green and purple workers equally) is fragile to small trembles in employers' beliefs. As they accumulate experience, employers begin to hire preferentially from the group who has invested more; as a consequence disadvantaged workers revise their expectations downwards, invest even less, and a robust pattern of discrimination persists for up to fifty rounds of the game.

An important difference between our experiment and earlier laboratory studies of discrimination is that our auctioneers are affiliated with one of the artificially induced groups (in Davis 1987, Fryer, Goeree and Holt 2005, and de Haan, Offerman and Sloof 2011, in contrast, the employers/auctioneers are neutral). Although this is not in principle necessary for discrimination to occur - people may be biased in favor of individuals who belong to other groups - we think it is a very natural and common feature of real-world discrimination. Moreover, inducing group identity in an environment with perfect information allows one to investigate whether group identity can generate unequal outcomes independently of statistical discrimination. As we shall see, discrimination does occur and is explained by a costless bias in auctioneers' decisions, when they allocate the prize among two or more high bids.

The tournament is meant to replicate the essential features of various real-world situations where discrimination may play an important role - from elections to political lobbying, research grant competitions, hiring and promotion decisions. Although we did not impose a specific interpretation on our laboratory task, the analogy with labor markets is quite compelling and we will use it to illustrate the logic of the experiment, its motivation, and its policy implications.

\footnotetext{
${ }^{5}$ De Haan et al. (2011) use a modified version of Fryer, Goeree and Holt's (2005) experimental setting, which is in turn inspired by Coate and Loury's (1993) model of statistical discrimination. Their key addition is a modicum of competition between workers.
} 
The paper is organized as follows: Section 2 describes the experimental set up and Section 3 provides a thorough analysis of the data. In Section 4 we outline a Bayesian model to explain bidders' learning pattern and to estimate their reaction function to auctioneers' decisions. Section 5 concludes summarizing the main results and articulating their significance for the study of discrimination.

\section{Experimental procedures and design}

The experimental study described in this paper was performed at the University of Parma, Italy, over two days in April and May 2011. We ran seven sessions with 140 subjects in total, using the standard procedures of experimental economics. Most subjects were in their low twenties, and studied business and economics. Average earnings were approximately 16 euro, for about one hour of experimentation. Auctioneers earned on average more than bidders (20 vs. 15 euro) but the greatest achievers in absolute terms were a small subset successful bidders, who took home as much as 28 euro.

The experiment consisted in two separate stages. In Stage 1 the social identity of experimental subjects was primed using a classic group identity manipulation. In Stage 2 the subjects participated in an experimental tournament with distinct roles (bidder or auctioneer) and group affiliations (Red or Blue).

Twenty subjects recruited by email participated in each session. As they entered the laboratory all subjects drew a colored ticket from an envelope and were randomly divided in two groups (named "Red" and "Blue"). Subjects were allowed to talk to each other and were asked to wear a colored bracelet that indicated their group affiliation. Each group then performed a simple cooperative task aimed at reinforcing their group identity: the goal was to memorize at least ten verses of a short poem in no more than five minutes, with another five minutes to write them down. The two groups performed the task in separate areas of the laboratory, under the supervision of an experimental assistant who did not interfere with their work but simply watched the time and monitored the results.

The task was designed to suggest a natural division of labor among the group members (each member could memorize one verse), and to almost guarantee the success of every group. Successful completion was rewarded with a prize of 30 euro, to be equally divided among the ten members of the group. ${ }^{6}$ Stage 1 of the experiment was meant to implement various conditions that, according to social psychologists, contribute to the creation of a group identity: physical proximity,

\footnotetext{
${ }^{6}$ All fourteen groups who participated in the experiment successfully completed the task, which they seemed to enjoy.
} 
face-to-face contact, perceptual similarity, interdependence, and common fate (Hogg and Abrams 2003).

At the end of this preliminary phase all players were asked to sit at their randomly assigned computer terminals, divided by partitions. We announced that another phase of the experiment was about to begin, and an assistant read the instructions aloud while the subjects followed on paper. Questions from the audience were elicited, until all misunderstandings had been resolved. At this point, Stage 2 of the experiment (the tournaments) began.

In a tournament the payoff of every agent depends on her relative performance, that is, how well she has done compared to other participants. A common way to determine payoffs in a tournament is to rank participants based on performance and to assign prizes in a descending order (the highest prize to the best performing agent, the second-highest prize to the second agent, and so on). In a labor-market tournament, for example, candidates compete by exerting effort, which affects their chances of being hired or promoted. The applicants who are not promoted suffer a cost that is equal to the additional investment in terms of effort that they have made, while effort is represented by a bid that is deducted at the end of the tournament. Hence, the game takes the form of an all-pay auction in which all bidders pay their bids regardless of whether they have won the prize or not, and the employer acts as an auctioneer who observes the bids and assigns the prize deciding which worker to promote. ${ }^{7}$

We implemented this setting experimentally letting each subject play a series of ten tournaments with identical parameters, in groups of five players: two Blue and two Red bidders participated in each tournament together with a Red or Blue auctioneer. The role of each subject (bidder or auctioneer) was randomly determined at the start and remained the same throughout the experiment. To eliminate potentially confounding effects, we used a "stranger" design where every subject was randomly allocated in a new group at every round. This was meant to prevent collusion among bidders, who might otherwise have tried to coordinate bids in such a way as to lower their investment costs. Bidders only knew the group affiliation of the other subjects involved in the tournament, while their personal identity was never disclosed. Although we did not make this explicit, we reshuffled within subgroups of 10 subjects ( 2 auctioneers and 8 bidders) that constitute our independent observations. ${ }^{8}$ The color of each bidder was either the same or different from the auctioneer's color. Following an established terminology in the experimental literature, we call ingroup members those bidders who shared the same color with the auctioneer and out-group

\footnotetext{
${ }^{7}$ On discrimination in experimental tournaments, see e.g. Bull, Schotter and Weigelt (1987), Schotter and Weigelt (1992).

${ }^{8}$ We obtained therefore two independent observations per session, or 14 in total.
} 
members those who did not. The in-group/out-group allocation remained fixed throughout the experiment. In other words: even though the auctioneer could change at every round, her color remained the same. Each bidder was either always in-group, or always out-group. Auctioneers faced two in-group bidders and two out-group bidders in every round.

In each round, every bidder received an endowment of 60 cents of a euro that she could invest to win a prize of 400 cents awarded by the auctioneer to a single bidder. Bidders were perfectly symmetric - we did not impose different investment costs - and their payoffs in each round were equal to their endowment minus their bid plus the prize (if they won). The endowment could not be accumulated over a series of rounds: after each round, whatever fraction of the endowment had not been spent was automatically added to the final earnings and a new endowment of 60 cents was provided for the next round. The auctioneer's payoff in contrast amounted to the winning bid she had chosen, multiplied by a factor of three (to increase the difference between bids).

The monetary payoffs were designed in such a way as to eliminate any rational incentive to underbid. Suppose in fact that the auctioneer is unbiased, i.e. that she chooses the highest bid and randomizes between equally high bids. The expected monetary value of a maximum bid (60 cents) is

$$
E V(\operatorname{bid} 60)=[0 \times(n-1) / n]+[400 \times 1 / n]=400 / n,
$$

where $n$ is the total number of players bidding 60. Since the expected monetary value of keeping her whole endowment is 60 cents, a rational risk-neutral player should always bid the maximum amount, even if the other three bidders are doing the same. Players always have the incentive to outbid their opponents or to match their proposal (if some opponents are choosing 60):

Equilibrium 1: Assuming a profit-maximizing (i.e. unbiased) auctioneer who randomizes to break ties, the unique Subgame Perfect Equilibrium is that every player chooses $60 .^{9}$

Our design differs from previous experiments where discrimination was induced imposing different investment costs on bidders. To make this setting particularly inhospitable to discrimination we also eliminated all sources of uncertainty, such as noisy signals or asymmetric knowledge of payoffs. In our experiment all monetary payoffs were common knowledge, and there could not be statistical discrimination - i.e. the investments (bids) were perfectly observed by

\footnotetext{
${ }^{9}$ Strictly speaking the auctioneer does not need to randomize in case of a tie for an equilibrium to exist. It is sufficient that she does not favor one of the colors "too much" (for quantitative analysis see below).
} 
auctioneers. Complete feedback about the bids submitted by the other three players, as well as the choice of the auctioneer, was provided after every round. So the only source of incomplete information was the possible discriminatory bias of the auctioneers, about which bidders had to form (and update) beliefs. Subjects did not receive information about the behavior of players who participated simultaneously in separate tournaments, nor about the history of play, apart from what they had directly experienced and memorized. ${ }^{10}$

Equilibrium 1 relies crucially on the assumption of auctioneer neutrality: the probability of winning the prize clearly declines if the auctioneer discriminates against some bidders. Suppose for example that a fraction $d$ of auctioneers discriminates against out-group players. The expected value of bidding the full endowment, given that one is an out-group bidder, then becomes:

$$
E V(\text { bid60 } \mid \text { out })=d \times 0+(1-d)[(0 \times(n-1) / n)+(400 \times 1 / n)]=400 / n-400 / n \times d,
$$

where $n$ is the total number of players bidding 60 . Given that $E V($ bid 0$)=60$, a risk-neutral outgroup player should bid nothing if she believes that $d>1-.15 n$. Notice that in principle auctioneers can always discriminate against out-group bidders without forfeiting any profits. The reason is that in-group bidders have an incentive to compete among themselves and to bid 60 even if they think that out-group players have no chance of being awarded the prize. Bids lower than 60 would grant the other in-group player a profitable opportunity to win by bidding the maximum amount. The necessary condition for an in-group player to bid 60 is that the probability of being awarded the prize is greater than .15 , which is always the case (as long as we assume no reverse discrimination) regardless of the behavior of out-group players. The behavior of the out-group bidders instead crucially depends on the fraction of discriminatory auctioneers $d$. Assuming common beliefs among out-group bidders and $d>0.4$ :

Equilibrium 2: Out-group players bid 0, while in-group players bid 60. Auctioneers of either type (discriminatory or fair) assign the prize to in-group players, since they submit strictly higher bids.

Note that bids in the interval $[1,59]$ can never be rationalized for either type of player. Assuming that bidders are (and believe that their opponents are) sufficiently sophisticated iterative reasoners, and that the auctioneer cares about monetary payoffs, the optimal bid is either zero or 60 . Even relaxing the strong assumption that players identify the equilibrium strategies via

\footnotetext{
${ }^{10}$ This contrasts with the design of de Haan, Offerman and Sloof (2011), who provided aggregate statistical feedback throughout the game.
} 
introspection, they should learn that bids in the interval $[1,59]$ cannot be part of an equilibrium by means of trial and error learning. Therefore, we expect bids in the interval $[1,59]$ to disappear with the repetition of the game.

To sum up, our experimental setting is characterized by multiple equilibria that depend on outgroup bidders' and auctioneers' behavior. In principle, we could observe:

1. symmetric bids and (a sufficient number of) unbiased auctioneers;

2. asymmetric bids and (a sufficient number of) discriminatory auctioneers.

In these two cases players' beliefs would be correct both at the beginning of the game and in equilibrium. However, there may also be self-confirming equilibria driven by false prior beliefs, such as

3. asymmetric bids driven by wrong prior expectations of discrimination (because the auctioneers are unbiased).

Case 3 may trigger a self-fulfilling mechanism à la Arrow, where incorrect priors lead to underinvestment, and this in turn generates unequal outcomes even without discriminatory auctioneers.

Which one of these equilibria is instantiated may depend of course on the dynamic of the game. Because beliefs may evolve during the experiment, we shall focus on bidders' "naïve" strategies at the beginning, as well as their behavior at the end of the game, after they have received feedback concerning the decisions of auctioneers. We shall try to test the following null hypotheses:

HYPOTHESIS 1: In-group and out-group players bid the same amount of money at the beginning of the game.

HYPOTHESIS 2: The behavior of in-group and out-group players does not change significantly in the course of the game.

HYPOTHESIS 3: In-group and out-group players bid on average the same amount of money at the end of the game.

Another set of hypotheses concerns the factors that determine behavior in equilibrium. First, we will examine the patterns of auctioneers' decisions to check if they are influenced by group membership.

HYPOTHESIS 4: Auctioneers are not willing to discriminate against out-group bidders. 
Notice that if discrimination does occur, it should be possible to measure its strength by means of the amount of money that auctioneers are willing to forfeit in order to satisfy their preference for in-group bids. It should also be possible to distinguish between case 2 and case 3 above, and ask whether discrimination is driven by auctioneers' decisions, given bidders' prior beliefs.

HYPOTHESIS 5: The behavior of bidders is not influenced significantly by auctioneers' decisions.

We try to test these hypotheses in the next section, where we describe the experimental data and provide a statistical analysis of the main findings.

\section{Results}

We begin our analysis with a general survey of auctioneers' and bidders' behavior. The aggregate pattern is represented in Figure 1 while the average bidding patterns of in-group and out-group players for the fourteen experimental sub-groups that constitute our independent observations is available in the on-line appendix (Figure A1). It is immediately apparent that in most groups and most rounds in-group players tended to bid more than out-group players. It is also apparent that this difference emerged early, but not immediately in the experiment: in the first round there was a prevalence of out-group bids. Once established, however, the in-group out-group difference was fairly robust throughout the game: in equilibrium, in-group players bid more.

[Figure 1 about here]

We test these propositions using data from all sessions. In-group players bid on average 33.1 cents in the first round, compared with 41.0 cents offered by out-group players. Since there has been no strategic interaction in the tournament before the first bid, we regard all the 112 bids as independent observations. The Mann-Whitney test finds the two distributions (of in-groups and outgroups) to be significantly different $(\mathrm{P}>|\mathrm{z}|=.046)$.

RESULT 1: Out-group players bid more than in-group players in the first round of the game.

This asymmetry however was reversed already in the second round, and the opposite trend persisted until the end of the experiment. The average bid throughout the ten periods is 43.1 cents 
for in-group players and 34.2 cents for out-group players and a Mann-Whitney test strongly rejects $(\mathrm{P}>|\mathrm{z}|=.005)$ the hypothesis that these averages are equal across the two groups (14 independent observations for in-group players and 14 independent observations for out-group players).

RESULT 2: In-group players bid more than out-group players throughout the game.

The first result is interesting because it suggests that the group identity manipulation administered in the first phase of the experiment did not discourage out-group bidders at the start. Strictly speaking, it is impossible to rule out the existence of expectations of discrimination in round one. It is conceivable that in-group players start bidding low under the expectation that they are going to be favored by auctioneers. Symmetrically, out-group players' rather bullish bidding may be interpreted as an attempt to compensate a perceived disadvantage - a phenomenon observed by Bull, Schotter and Weigelt (1987) in a different context. In any case, these strategies are evidence against the hypothesis that incorrect priors trigger a self-fulfilling mechanism of discrimination. Behavior in the first round should be taken with a pinch of salt, for it certainly reflects a certain amount of confusion and mistaken beliefs. Intermediate bids (bids between zero and sixty cents), should not be observed if players are sophisticated iterative reasoners. Table 1 summarizes the percentage of maximum (60), minimum (0) and intermediate bids $(0>$ bid $>60)$ submitted by in-group and out-group players across the ten rounds of the experiment. We observe in both groups a decline of intermediate bids, from $60-70 \%$ in period 1 to about $20 \%$ in period 10 , which suggests that a process of learning has taken place during the course of the experiment. (It is noteworthy that the sharpest reduction in intermediate bids occurred after the first period, and that learning was probably over by period six.)

[Table 1 about here]

According to an alternative interpretation, intermediate bids may be collusion signals, especially in early rounds, i.e. attempts to let other bidders know that one is willing to try to reduce competition so as to keep the price low. However, the experimental environment is particularly inhospitable to collusion (no communication, anonymity, and "strangers" design) so unsurprisingly collusion fails. ${ }^{11}$ Since players are rematched at every round, in-group subjects are unable to collude

\footnotetext{
${ }^{11}$ This is consistent with a vast amount of data from repeated public goods experiments (Ledyard 1995). Notice incidentally that the returns of opportunistic behavior are much greater in this game than in a classic public good game, given that the largest portion of the earnings (the prize) is assigned on a strictly competitive basis. Harbring and
} 
even when out-group players reduce their bids significantly. Given that the prize went in the overwhelming majority of cases to a player who bid 60 , it seems reasonable to conclude that the remaining intermediate bids reflect out-of-equilibrium beliefs, if not plain irrationality.

In light of these data, and following a useful convention in experimental economics, we consider behavior at the end of the game as most indicative of players' preferences and beliefs in equilibrium. We take data from the last three rounds. Here the average bids amount to 44.0 for ingroup players and 33.6 for out-group players, a difference that is statistically significant across the 14 pairs of independent observations at $\mathrm{P}>|\mathrm{z}|=.03$ (Mann-Whitney). ${ }^{12}$

RESULT 3: In-group players bid more than out-group players at the end of the game.

Table 1 shows that at the end of the game $64 \%$ of in-group players bid the maximum amount (60 cents), compared with only $46 \%$ of out-group players. This difference however was already manifest in period three, and persisted with minor variations thereafter. So it is not surprising that in-group players were on average more successful than out-group players, winning 180 out of 280 tournaments (64.3\%). At the end of the experiment, in-group bidders took home on average 17.5 euro, compared with 12.7 euro earned by out-group bidders. Figure 2 summarizes the proportion of winning bids by in- and out-group players during the course of the experiment, aggregating across all sessions. Notice that in-group players won the majority of tournaments in every round but one (round nine). What has to be explained is whether the behavior of auctioneers was overall rational, in the sense that they tended to maximize their profits by choosing the highest bids, or was instead driven by discriminatory tastes.

[Figure 2 about here]

In order to test this proposition we have to look more carefully at auctioneers' decisions. Table 2 reports the decisions made by auctioneers, given the distribution of high bids in the

Irlenbusch (2008) also observe very little collusion in experimental tournaments with more than two contestants. Sutter and Strassmair (2009) find that, unsurprisingly, collusion increases when communication is allowed.

${ }^{12}$ The difference (42.4 vs. 33.3) is statistically significant also taking the average of the last two rounds $(\mathrm{P}>|\mathrm{z}|=.08)$, while despite the similarity in magnitude (42.7 vs. 32.4) it is not significant if we focus on the last period only (P > $|\mathrm{z}|$ $=.15)$, due to a much higher variance in the data. 
tournaments. ${ }^{13}$ In the first two columns ("Highest bids made by") we list the eight possible combinations of high bids depending on their number (zero, one, two), and their type (in- or outgroup); the third and fourth columns ("Number of winners") report the decisions of auctioneers for each combination of high bids. For example: the first line includes data from all tournaments where two in-group players submitted the highest bids. This happened 27 times in the experiment (last column), and in 23 cases (third column) the auctioneer awarded the prize to an in-group player (in other words, she maximized her profits $85 \%$ of the time).

\section{[Table 2 about here]}

It is instructive to compare the top two lines with the bottom two lines of Table 2, that include data about the tournaments in which the high bids were submitted by players of the same color. These data allow testing the existence of costly discrimination: assigning the prize to an ingroup player while the highest bid has been made by an out-group subject implies a cost for the auctioneer. This happens 9 out of 81 times (11.1\%). Similarly, choosing a lower out-group bid when the highest bid is made by in-group players can be considered a case of "reverse" costly discrimination, which is observed in 4 out of 39 tournaments (10.2\%). In either circumstance, the auctioneers chose in the overwhelming majority of cases to give the prize to one of the high bids. Moreover, according to a Fisher Exact Test the frequency of costly decisions is not significantly different when favoring in-group vs. out-group players $(p=0.25)$. Given the low frequency and the symmetry of these data we conclude that they should be considered random variations in an otherwise systematically rational pattern of auctioneers' behavior.

RESULT 4a: Auctioneers do not discriminate against out-group bidders when discrimination is costly.

Lines 3 to 6 in Table 2 (shaded) include data about tournaments where high bids were submitted by in-group and out-group players at the same time. We shall refer to these cases as tiebreaks. Tie-breaks are an important element of our experiment, for they provide auctioneers with an opportunity to engage in costless discrimination. In tie-breaks auctioneers may send a discriminatory signal while still maximizing their profit. This is not an unrealistic event, given that in many real circumstances an employer is likely to face several equally qualified applicants. Notice

\footnotetext{
13 "High bid" from now on means the highest submitted bid in a given round. Since the bidders are symmetric (they have the same endowment), there must be at least one and there cannot be more than four high bids per tournament.
} 
that in such a case it would be inappropriate to speak of a preference for discrimination, because auctioneers would not be willing to pay a monetary cost to engage in favoritism. To distinguish, we shall speak of a discriminatory bias in tie-breaks.

There was a pronounced asymmetry in the choices of auctioneers in tie-breaks, with prizes going to out-group members only 56 out of 160 times. Such a distribution of outcomes is unlikely to be the product of chance. In fact, if we mimic an unbiased auctioneer with a probability .5 that the prize is assigned to out-group players, the binomial cumulative probability of obtaining at most 56 successes out of 160 trials amounts to $\mathrm{p}=.00005$. The number of high bids submitted by each type of player does not affect the result significantly: when auctioneers were choosing between an equal number of in-group and out-group high bids, in-group players won the tournament $66 \%$ of the time. When two high bids out of three were submitted by in-group members, their probability of winning was $68 \%$. When two out of three high bids were submitted by out-group players, in-group players won $52 \%$ of the tournaments.

RESULT 4b: Auctioneers favor in-group members when discrimination is costless (in tie-breaks).

Tie-break discrimination can be explained in various ways: first, the bias may reflect an asymmetry in auctioneers' motives (a desire to benefit in-group players). Alternatively, auctioneers may conform to a perceived norm: the group labels may suggest that they are expected to favor ingroup and discriminate against out-group players. The latter explanation is in line with psychologists' interpretation of the minimal group as a "demand effect", albeit of an especially interesting kind. The manipulation may act as a cue activating a set of norms that in real life we typically use to regulate group behavior. ${ }^{14}$

\footnotetext{
${ }^{14}$ Tajfel discusses the demand effect interpretation as follows: "what was no more than a hint from the experimenters about the notion of 'groups' being relevant to the subjects' behavior had been sufficient to determine, powerfully and consistently, a particular form of intergroup behavior. [...] The problem then must be restated once again in terms of the need to specify why a certain kind of intergroup behavior can be elicited so much more easily than other kinds [...]. [T]he subjects structured the situation for themselves as one involving relations between groups, and [...] they behaved in ways similar to those habitual to them in situations of this kind" (1982: 235-6). There is evidence that subjects are not particularly concerned about the expectations of the experimenter, since removing mutual knowledge of group membership makes the group identity effect disappear (e.g. Yamagishi, Jin and Kiyonari 1997, Güth, Ploner and Regner 2009), so the minimal group should be considered as a "peer demand effect", rather than an "experimenter's demand effect". This also suggests that group identity relies on a complex system of mutual expectations, reflecting the social pressure to conform to what peers imply it is the socially acceptable norm. On demand effects in general, see Zizzo (2010).
} 
Interestingly, a tie-break bias has also been observed by de Haan, Offerman and Sloof (2011) in their experiment on statistical discrimination. De Haan and co-authors report the decisions of color-neutral auctioneers who receive noisy signals regarding the investments of two bidders (labelled green and purple). The signals can be either "high" or "low", and auctioneers make profits only if they assign the prize to a truly high bid. After a few rounds a clear pattern of discrimination emerges spontaneously, where bidders from one group (the "advantaged group") on average invest more and are chosen more frequently by auctioneers. However, there is no sign of "overt" discrimination in the data: when they receive different signals, auctioneers tend to choose the high bid even if it comes from the disadvantaged group. The majority of employers rather implement a form of tie-break discrimination, choosing $81 \%$ of the time the bid from the advantaged group when they receive two high signals. De Haan et al. (2011) show that this strategy is part of an equilibrium, provided there is a substantial proportion of fair auctioneers who do not discriminate at all. Such an equilibrium does not exist in our setting - where there is no uncertainty due to noisy signals because out-group bidders have clear dominant strategies that depend on the proportion of discriminatory auctioneers (expressed by parameter $d$ ). Nevertheless, we do observe a mix of different strategies chosen by out-group bidders, which is explained by the different streams of feedback they have received in the course of the game. We analyse bidders' reactions to auctioneers' decisions in the next section of the paper.

\section{A Bayesian model of learning}

In- and out-group bids began to diverge already in round two, and were more or less stable by round five. In the first round in-group bidders won almost $60 \%$ of the tournaments, even though they submitted on average lower bids. Consider however that aggregate data were not available to individual bidders during the game. Each player could only observe the distribution of bids and the outcome of the auctions in which she was directly involved. The interesting question then is how this feedback was processed, and how it influenced bidders' strategies as they collected more evidence about auctioneers' behavior.

At the beginning of the game bidders did not know whether the auctioneers were going to favor in-group members and discriminate against out-group players. They could make conjectures, of course, but given that out-group bidders did not bid less than in-group players in the first round, it is reasonable to assume that bidders entered the game with a prior probability estimate not too far from 0.5, which is equivalent to assuming that possible expectations of discrimination were not sufficiently strong to deter positive bids. Starting from the first round, bidders received signals 
regarding auctioneers' discriminatory tastes. Learning can be represented as an updating process of each individual's (estimated) likelihood that the prize will be assigned to a bid submitted by a member of her group, given the meaningful signals that she received as the game proceeded.

A signal is meaningful if it provides useful information regarding auctioneers' propensity to discriminate. If all high bids have been submitted by in-group bidders, for example, and the auctioneer assigns the prize to a high bid, the signal is not meaningful according to our definition, since the choices of a biased and of an unbiased auctioneer would coincide. If there is a tie, in contrast, and the auctioneer chooses an in-group bidder, the signal may be interpreted as evidence of discrimination. Figure 3 shows that out-group members react strongly to negative signals, with an average drop in the average bid (at time $t$ ) of more than 10 cents following an unfavorable meaningful signal (at $t-1$ ). Such a reaction is not observed in the case of in-group players, who instead tend to lower their bids by about 4 cents when they have been favored in a tie or when they have just won with a lower bid.

[Figure 3 about here]

It is worth emphasizing that the entire reduction of in-group bids is due to the individual who wins the prize, while the same-color opponent displays no reaction on average. Hence, this reaction to the outcome of the immediately preceding round seems to reflect a sort of gambler's fallacy ("you can't be lucky twice in a row") rather than strategic thinking or learning. In any case, although the pattern in Figure 3 is informative, it does not exploit all the information available in the data. In particular, it does not capture the reaction of bidders to the whole stream of signals they have received up until time $t$. In the rest of this section we explain bidders' behavior using a Bayesian updating model that exploits the informative content of every signal received by bidders in the course of the game.

We model the situation that bidders face as a sampling problem from an urn with an unknown proportion of "in" and "out" balls, with replacing at every round. If the fraction of "in" and "out" balls is not the same, the urn represents auctioneers' stochastic propensity to discriminate. Bidders try to learn the true value of that propensity observing a sequence of draws from the urn (auctioneers' decisions). At each round a bidder observes one ball (decision) and updates her probability estimate of the in/out ratio of balls in the urn.

Bidders' beliefs about the composition of the urn can be conveniently represented using a Beta distribution, the shape of which is characterized by two parameters $(\alpha, \beta)$. At the beginning of the game, when no signal has been observed yet, we can interpret the parameters of the Beta 
distribution as already incorporating a number of hypothetical positive and negative signals equal to $\alpha-1$ and $\beta-1$, respectively. For instance, prior expectations that take the form of a Beta $(1,1)$ are equivalent to assuming an entirely open-minded bidder who assigns a uniform probability over the whole $[0,1]$ spectrum, as if no hypothetical signal has been already incorporated. (The uniform distribution is in fact a special case of the Beta distribution.)

There are of course other possibilities, but as long as the symmetry is preserved $(\alpha=\beta)$ higher values correspond to steeper bell-shaped distributions with a mean of 0.5 , i.e. they correspond to the beliefs of a bidder who expects to meet an unbiased auctioneer. For instance, a $\operatorname{Beta}(2,2)$ corresponds to the beliefs of a bidder who expects to face a fair auctioneer, as if she had already observed one positive and one negative signal. Intuitively, the higher the prior value of the two parameters, the stronger her initial confidence that she is facing a fair auctioneer, and the slower the convergence of her beliefs towards the true composition of the urn, as new evidence accumulates.

The values of $\alpha$ and $\beta$ do not need to coincide. Different values represent the beliefs of a bidder who expects to face a biased auctioneer. The higher $\beta$ is relative to $\alpha$, the more skewed to the right the distribution is, and the higher the expectation of being discriminated against. We initially assume that both in-group and out-group bidders are characterized by a Beta $(1,1)$, i.e. that both populations are characterized by prior expectations of facing an unbiased auctioneer, but robustness checks will be performed to take into account alternative specifications.

In subsequent rounds, beliefs are updated in a Bayesian manner, given the signals that are actually observed. The characteristics of a Beta combined with a binomial distribution imply that posterior beliefs are also distributed as a Beta with the parameter $\alpha(\beta)$ increasing one unit at a time as each positive (negative) signal is observed. As explained earlier, we assume that the updating process is triggered only by meaningful signals, i.e. either by choices that imply costly discrimination or by tie-break decisions.

The next step is to estimate the reaction function of each type of player (in-group and outgroup), defined as the relation between the likelihood that one's color is going to win and the submitted bid. The goal is to account for players' behavior given their expectations throughout the whole game, but especially in the early rounds of the experiment where the most drastic adjustment in bidders' behavior takes place. We estimate the reaction function using the following empirical specification:

$$
B_{i, t}=\gamma_{0}+\gamma_{1} L_{i, t}+\gamma_{2} L_{i, t}^{2}+\gamma_{3} L_{i, t} * O U T+\gamma_{4} L_{i, t}^{2} * O U T+\varepsilon i, t,
$$


where $B_{i, t}$ is the bid submitted by player $i$ at time $t, L$ is the likelihood that the prize will be assigned to a bidder of one's own type, and the $\gamma s$ are parameters. The dummy variable OUT is introduced to account for the possibility that the reaction functions of in- and out-group players differ, or in other words that bidders from different groups react differently to the same signals. This is necessary to account for the possible effect of the group identity manipulation we introduced in phase one of the experiment. Moreover, the model accounts for possible non-linearities. Given the nature of dynamic panel of the data, in which the bid in every period depends on the whole history of signals observed, an OLS estimate would return biased and inconsistent estimates. Hence, we estimate it using GMMtype instruments for the difference equation and computing the standard errors with the ArellanoBond robust VCE estimators.

[Table 3 about here]

Results are presented in the first column of Table 3 and show that the hypothesis of different reaction functions is not supported by the data. In fact, the interaction terms are not significant. This suggests that the unequal achievements observed in our experiment are driven by auctioneers' decisions, rather than by prior expectations of discrimination, or by a difference in the reaction functions of in-group and out-group players.

[Figure 4 about here]

The shape of the reaction function implied by the estimated coefficients is represented in Figure 4. The vertical line marks the $50 \%$ likelihood (the belief that the auctioneer is unbiased). A second interesting feature of the estimated reaction function is that both in-group and out-group players reacted asymmetrically to positive and negative information: if they believed that the auctioneer was discriminating against them, they reduced their bids more than they were willing to increase them if they believed that she was biased in their favor. Hence the asymmetric reactions of Figure 3 completely disappear when the whole history of play is taken into account.

From a theoretical point of view, the bid of a risk-neutral out-group bidder who expects all her opponents to bid the whole endowment jumps from 60 to 0 around a probability equal to 0.4 , as we have seen. However, no such discontinuity can be detected in our data. If we estimate a specification including a cubic term, to allow the model to fit a possible inflection point around the 0.4 likelihood, all coefficients lose significance. As a robustness check, we also test models with different prior beliefs. Our results do not change qualitatively if we assume that out-group bidders 
have mild prior expectations of being discriminated against, i.e. a probability of winning about $1 / 3$ summarized by a Beta(1,2), while in-group players believe that the auctioneer is unbiased. Coefficients are reported in the second column of Table 3. More generally, the specification and the results are robust to small perturbations of prior beliefs that go in the right direction (i.e. in-group players are more likely to win), provided the priors are flexible enough to quickly adapt to the evidence that accumulates in each period. ${ }^{15}$ An alternative specification with stickier prior beliefs, for instance as reflected by a $\operatorname{Beta}(2,2)$, would be unable to fit the data.

RESULT 5: Assuming Bayesian updating of flexible priors, all players (in-group and out-group) react in the same way to signals, but are more sensitive to negative than to positive signals.

This suggests that the group identity manipulation did not have an effect on the way in which bidders interpreted or reacted to the signals sent by auctioneers. The main difference - which explains the decay of their bids - is that out-group players received a greater number of negative signals induced by costless discrimination early in the game, compared to their in-group fellows. This created negative expectations of discrimination, which led to a reduction in out-group bids. In equilibrium, auctioneers engaged in costless discrimination, out-group players bid less, and as a consequence achieved less in spite of perfectly symmetric costs and the absence of statistical discrimination.

\section{Conclusion}

Models that postulate preferences for discrimination are vulnerable to a simple objection: such preferences create arbitrage opportunities that should be exploited by non-discriminating firms in a competitive market. In this paper we have reported data from an experiment with artificially created group identities, where discrimination emerged quickly and persisted through time in spite of competition. The basic setting is a tournament (all-pay auction) where four bidders submit offers to an auctioneer, who has an incentive to assign a monetary prize to the highest bid. Bidders are completely symmetric, and in equilibrium should submit identical bids if the auctioneer is unbiased. Using a classic device from social psychology, we induced a slight bias in auctioneers' decisions. This bias turned out to be strong enough to deter high bids from out-group players, but not enough to create a costly preference for discrimination.

\footnotetext{
${ }^{15}$ Of course, this does not hold if beliefs are widely mistaken. For instance, assuming prior beliefs that out-group players are more likely to win would lead to significantly different reaction functions across groups.
} 
Further analysis reveals that discrimination is mainly driven by auctioneers' behavior. Even if out-group subjects had no expectations of discrimination at the beginning of the experiment, large and significant differences between the bids (and outcomes) of the two groups emerged quickly with repetition. This is the effect of two mechanisms: on the one hand, bidders received signals that indicated a mild discriminatory bias in auctioneers' decisions, and updated their expectations accordingly. On the other, bidders strongly reacted to negative signals, and drastically revised their bids downwards. Discrimination, thus, was sustained by players' reactions to positive/negative signals, combined with the fact that out-group players received more negative signals, rather than by an anomalous reaction of out-group bidders.

These observations have various interesting implications. The first one is that a mere (noncostly) bias in favor of in-group bidders may suffice to induce persistent discrimination in a market environment. Such discrimination may be invulnerable to competition, and thus may be likely to persist even if auctioneers can observe the true quality of submitted bids. Another set of considerations concern the policies that may be implemented to prevent or reduce discrimination in the marketplace. If tie-breaks play an important role in the emergence of discrimination (as suggested by our experiment as well as the experiment of de Haan, Offerman and Sloof 2011), policies like the UK 2010 Equality Act, which invite employers to favor the members of disadvantaged groups when they are at least as qualified as other candidates, may seem to be aiming at the right target. However, it is important to realize that tie-breaks are typically "fuzzier" in reality than in our experimental environment. While identifying two identical bids is straightforward in the laboratory, where monetary payoffs provide a clear measure of economic benefit, in real-life situations auctioneers may be able to hide discrimination behind qualitative considerations that cannot be validated in a straightforward objective manner. When she assesses two job applicants with roughly equal qualifications, for example, an employer with discriminatory tendencies may appeal to ambiguous factors such as extra-curricular experience, general attitude, performance in interviews, and so forth, in order to break the lock and make one of the candidates look better. (This problem will be exacerbated if the bias is partly subconscious.) In such cases, a mere legislative "nudge" to favor minority candidates in tie-breaks would turn out to be ineffective, while traditional policies based on tax-breaks or subsidies might be more efficacious in correcting biases towards the members of a social group. 


\section{References}

Akerlof, G. and Kranton, R. (2010) Identity Economics: How Our Identities Shape Our Work, Wages, and Well-Being. Princeton: Princeton University Press.

Altonji, J.G. and Blank, R.M. (1999) "Race and Gender in the Labor Market", in Handbook of Labor Economics, Vol. 3, ed. by O. Ashenfelter and D. Card. Amsterdam: North Holland.

Anderson, L.R., Fryer, R.G., and Holt, C.A. (2006) "Discrimination: Experimental Evidence from Psychology and Economics", in Handbook of the Economics of Discrimination, ed. by W.M.

Rodgers. Cheltenham: Edward Elgar.

Arrow, K.J. (1973) “The Theory of Discrimination" in Discrimination in Labor Markets, ed. by O. Ashenfelter and A. Rees. Princeton: Princeton University Press, 3-33.

Bacharach, M. (2006) Beyond Individual Choice: Teams and Frames in Game Theory. Princeton: Princeton University Press.

Becker, G.S. (1957) The Economics of Discrimination. Chicago: University of Chicago Press.

Benjamin, D.J., Choi, J.J. and Strickland, A.J. (2010) "Social Identity and Preferences", American Economic Review 100: 1913-28.

Bernhard, H., Fehr, E. and Fischbacher, U. (2006) "Group Affiliation and Altruistic Norm Enforcement”, American Economic Review 96: 217-221.

Bowles, S. and Gintis, H. (2011) A Cooperative Species: Human Reciprocity and Its Evolution. Princeton: Princeton University Press.

Bull, C., Schotter, A. and Weigelt, K. (1987) "Tournaments and Piece Rates: An Experimental Study", Journal of Political Economy 95: 1-33.

Cain, G.G. (1986) "The Economic Analysis of Labor Market Discrimination: a Survey", in Handbook of Labor Economics, ed. by O. Ashenfelter and R. Layard. Amsterdam: North Holland, 693-785.

Charness, G., Rigotti, L. and Rustichini, A. (2007) "Individual Behavior and Group Membership", American Economic Review 97: 1340-1362.

Chen, Y. and Xin Li, S. (2009) "Group Identity and Social Preferences", American Economic Review 99: 431-457.

Choi, J.K. and Bowles, S. (2007) "The Coevolution of Parochial Altruism and War", Science 318: 636-640.

Coate, S. and G. Loury, 1993: "Will Affirmative Action Eliminate Negative Stereotypes?", American Economic Review 83: 1220-1240.

Darity, W. A, and Mason, P.L. (1998) "Evidence on Discrimination in Employment: Codes of Color, Codes of Gender”, Journal of Economic Perspectives 12: 63-90. 
Davis, D.D. (1987) “Maximal Quality Selection and Discrimination in Employment", Journal of Economic Behavior and Organization 8: 97-112.

de Haan, T., Offerman, T. and Sloof, R. (2011) "Discrimination in the Labor Market: The Curse of Competition between Workers", Tinbergen Institute Discussion Paper 2011-174/1.

Eckel, C. and Grossman, P. (2005) "Managing Diversity by Creating Team Identity", Journal of Economic Behavior and Organization 58: 371-392.

Efferson, C., Lalive, R. and Fehr, E. (2008) "The Coevolution of Cultural Groups and Ingroup Favoritism", Science 26: 1844-1849.

Fang, H. and A. Moro (2011) "Theories of Statistical Discrimination and Affirmative Action: A Survey", in Handbook of Social Economics, Vol. 1A, ed . by J. Matthew, O. Jackson, and A. Bisin: North-Holland, 133-200.

Feltovich, N. and Papageorgiou, C. (2004) “An Experimental Study of Statistical Discrimination by Employers", Southern Economic Journal 70: 837-849.

Filippin, A. (2008) “Discrimination and Workers' Expectations: a View from the Lab”, mimeo.

Fershtman, C. and Gneezy, U. (2001) "Discrimination in a Segmented Society: An Experimental Approach”, Quarterly Journal of Economics 116: 351-377.

Fershtman, C., Gneezy, U. and Verboven, F. (2005) "Discrimination and Nepotism: The Efficiency of the Anonimity Rule", Journal of Legal Studies 34: 371-396.

Fryer, R.G., Goeree, J.K. and Holt, C.A. (2005) "Experience-based Discrimination: Classroom Games", Journal of Economic Education 36: 160-70.

Goette, L., Huffman, D., Meier, S. and Sutter, M. (2010) "Group Membership, Competition and Altruistic Versus Antisocial Punishment: Evidence from Randomly Assigned Army Groups”, IZA Discussion Paper No. 5189.

Güth, W., Ploner, M. and Regner, T. (2009) "Determinants of In-group Bias: Is Group Affiliation Mediated by Guilt Aversion?", Journal of Economic Psychology 30: 814-27.

Harbring, C. and Irlenbusch, B. (2008) "How Many Winners Are Good to Have? On Tournaments with Sabotage", Journal of Economic Behavior and Organization 65: 682-702.

Hargreaves Heap, S. and Zizzo, D. (2009) "The Value of Groups", American Economic Review 99: 295-323.

Hogg, M.A. and Abrams, D. (2003) "Intergroup Behavior and Social Identity", in The Sage Handbook of Social Psychology, ed. by M.A. Hogg and J. Cooper. London: Sage, pp. 407-423.

Ledyard, J. (1995) "Public Goods: A Survey of Experimental Research", in The Handbook of Experimental Economics, ed. By J. Kagel and A. Roth. Princeton University Press.

Phelps, E.S. (1972) "The Statistical Theory of Racism and Sexism”, American Economic Review 62: 659-661. 
Richerson, P. and Boyd, R. (2001) "The Evolution of Subjective Commitment to Groups: A Tribal Instincts Hypothesis", in The Evolution of Subjective Commitment, ed. by R.M. Nesse. Russell Sage Foundation.

Rodgers, W.M. (ed. 2006) Handbook of the Economics of Discrimination. Cheltenham: Edward Elgar.

Ruffle, B.J. and Sosis, R. (2006) "Cooperation and the In-group-out-group Bias: A Field Test on Israeli Kibbutz Members and City Residents", Journal of Economic Behavior and Organization 60: 147-163.

Schotter, A. and Weigelt, K. (1992) "Asymmetric tournaments, equal opportunity laws, and affirmative action: some experimental results", Quarterly Journal of Economics 107: 511-39

Sherif, M., Harvey, O., White, B., Hood, W. and Sherif, C. (1961) Intergroup Conflict and Cooperation: The Robbers Cave Experiment. Norman: University of Oklahoma Book Exchange.

Sugden, R. (2000) “Team Preferences”, Economics and Philosophy 16: 174-204.

Sutter, M. and Strassmair, C. (2009) "Communication, Cooperation and Collusion in Team Tournaments - An Experimental Study”, Games and Economic Behavior 66: 506-525.

Tajfel, H. (1982) Human Groups and Social Categories. Cambridge University Press.

Tajfel, H., Billig, M., Bundy, R. and Flament, C. (1971) "Social Categorization and Intergroup Behavior”, European Journal of Social Psychology 1: 149-178.

Yamagishi, T., Jin, N. and Kiyonari, T. (1999) "Bounded Generalized Reciprocity: Ingroup Boasting and Ingroup Favoritism”, Advances in Group Processes 16: 162-197.

Zizzo, D.J. (2010) "Experimenter Demand Effects in Economic Experiments", Experimental Economics 13: 75-98.

Zizzo, D.J. (2011) "You Are Not in My Boat: Common Fate and Discrimination against Outgroup Members", International Review of Economics 58: 91-103. 


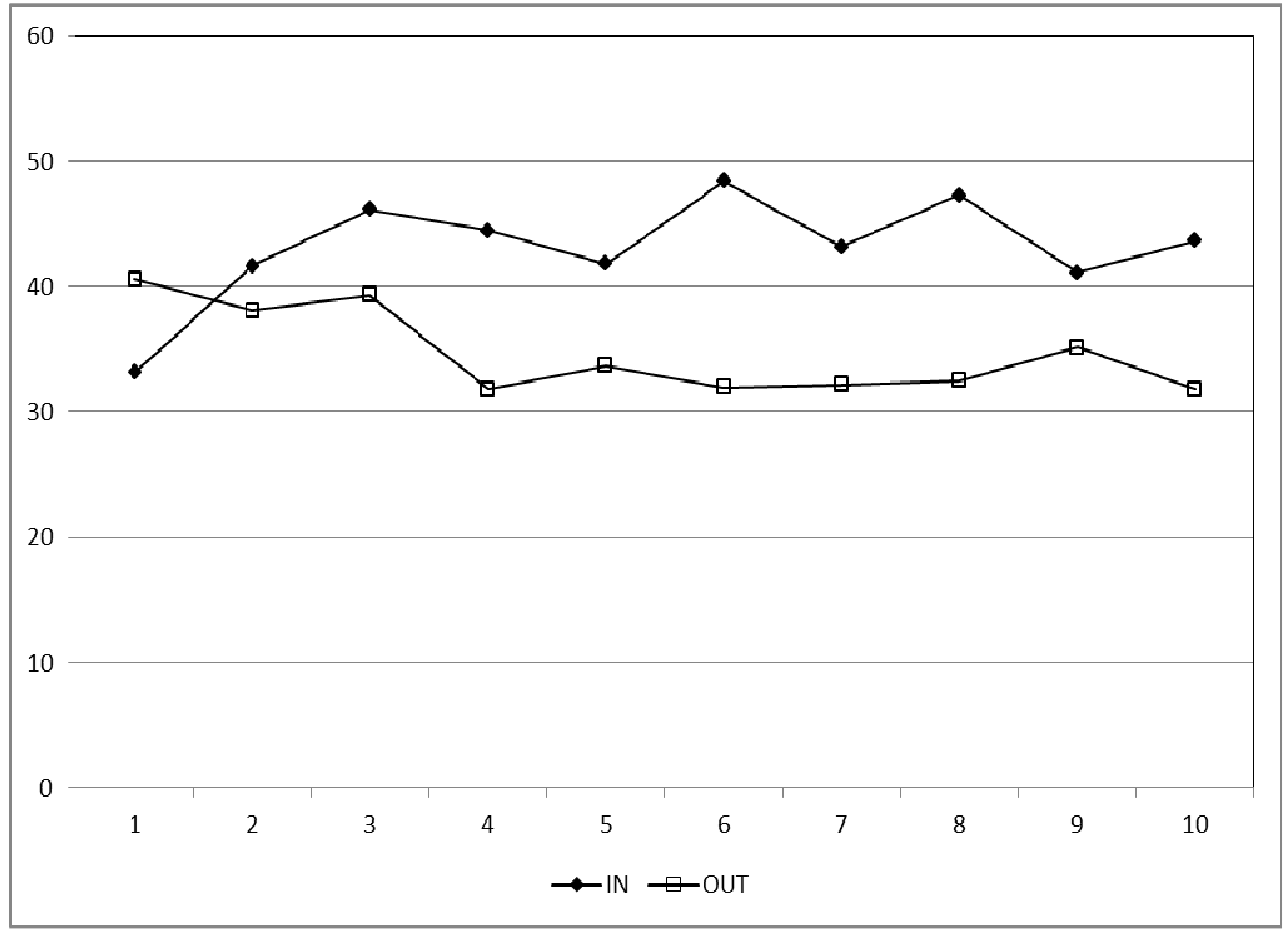

Figure 1: Average bidding patterns (aggregate) 


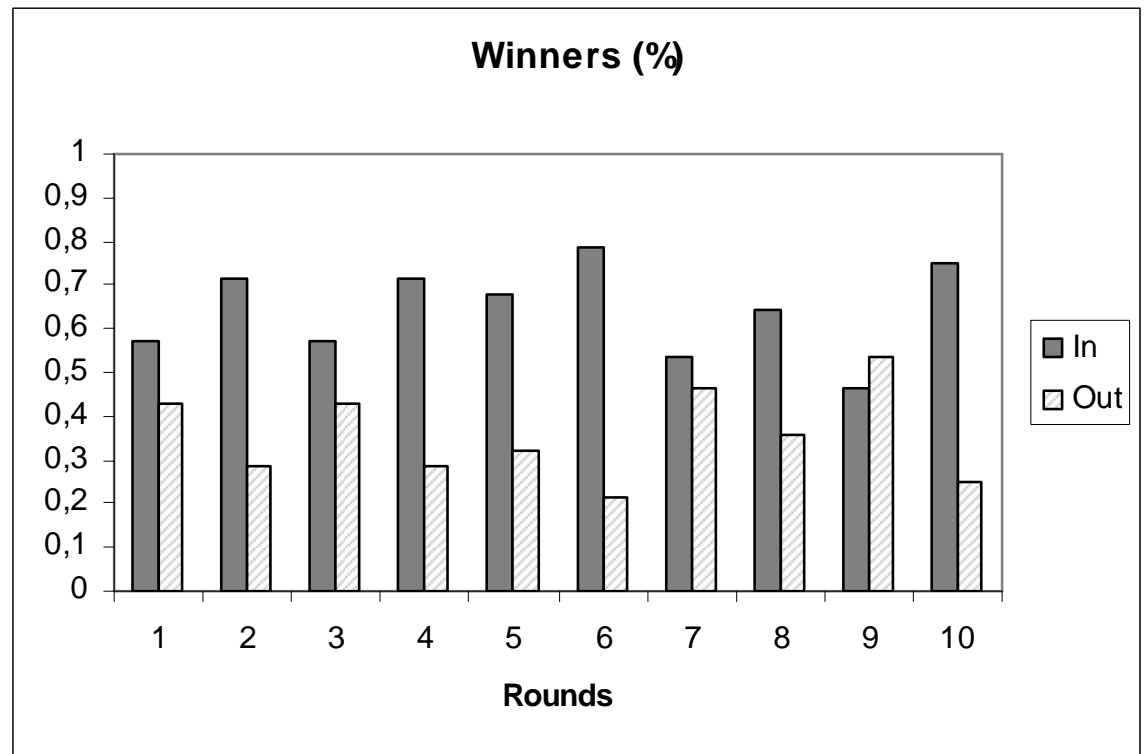

Figure 2: Proportion of winners per type of bidder, in each round 


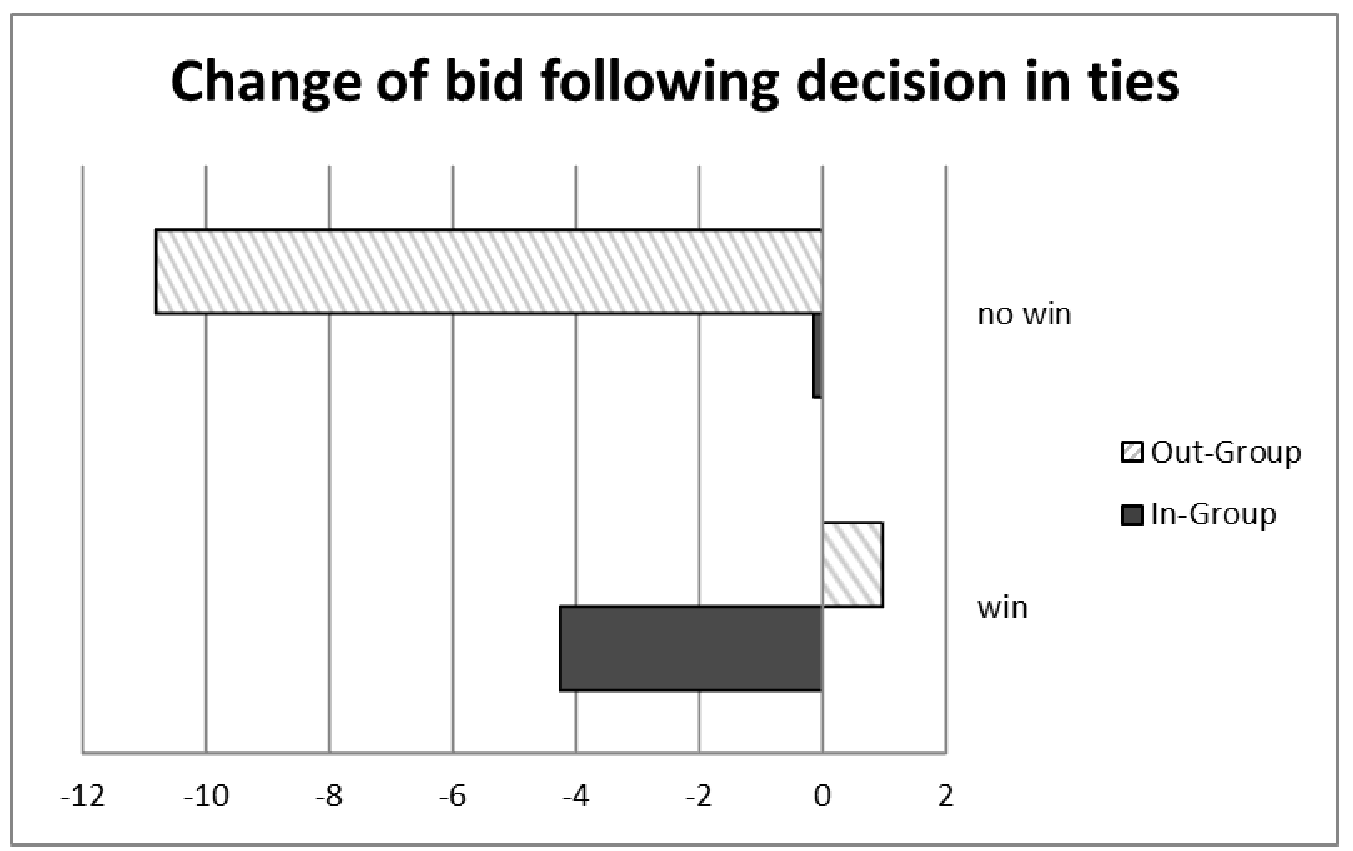

Figure 3: Average change of bid for in-group and out-group players following a positive vs. negative decision in a tie 




Figure 4: Bidders' reaction function, assuming a $\operatorname{Beta}(1,1)$ prior and posteriors that follow the stream of positive and negative meaningful signals. Winning likelihoods (expectations) are on the horizontal axis, the level of bids on the vertical axis. Dashed line for values of probability never observed in the sample. 


\begin{tabular}{|c|c|c|c|c|c|c|}
\hline & & IN & & & OUT & \\
\hline Round & $\mathbf{0}$ & $\mathbf{0 < \text { bid } < \mathbf { 6 0 }}$ & $\mathbf{6 0}$ & $\mathbf{0}$ & $\mathbf{0 < \text { bid<60 }}$ & $\mathbf{6 0}$ \\
\hline $\mathbf{1}$ & 0.05 & 0.70 & 0.25 & 0.02 & 0.59 & 0.39 \\
\hline $\mathbf{2}$ & 0.09 & 0.46 & 0.45 & 0.16 & 0.44 & 0.41 \\
\hline $\mathbf{3}$ & 0.10 & 0.30 & 0.60 & 0.20 & 0.34 & 0.46 \\
\hline $\mathbf{4}$ & 0.12 & 0.33 & 0.55 & 0.20 & 0.42 & 0.38 \\
\hline $\mathbf{5}$ & 0.14 & 0.27 & 0.59 & 0.32 & 0.34 & 0.34 \\
\hline $\mathbf{6}$ & 0.11 & 0.14 & 0.75 & 0.34 & 0.20 & 0.46 \\
\hline $\mathbf{7}$ & 0.18 & 0.18 & 0.64 & 0.28 & 0.27 & 0.45 \\
\hline $\mathbf{8}$ & 0.14 & 0.15 & 0.71 & 0.32 & 0.22 & 0.46 \\
\hline $\mathbf{9}$ & 0.25 & 0.18 & 0.57 & 0.34 & 0.18 & 0.48 \\
\hline $\mathbf{1 0}$ & 0.13 & 0.23 & 0.64 & 0.36 & 0.18 & 0.46 \\
\hline
\end{tabular}

Table 1: Polarization of bids in the course of the experiment

\begin{tabular}{|c|c|c|c|c|}
\hline \multicolumn{2}{|c|}{ Highest bids made by } & \multicolumn{2}{c|}{ Number of winners } & \\
\hline IN & OUT & IN & OUT & Total \\
\hline 2 & 0 & 23 & 4 & 27 \\
\hline 1 & 0 & 49 & 5 & 54 \\
\hline 2 & 1 & 35 & 16 & 51 \\
\hline 2 & 2 & 15 & 4 & 19 \\
\hline 1 & 1 & 41 & 24 & 65 \\
\hline 1 & 2 & 13 & 12 & 25 \\
\hline 0 & 1 & 2 & 27 & 29 \\
\hline 0 & 2 & 2 & 8 & 10 \\
\hline & & $64.3 \%$ & $35.7 \%$ & 280 \\
\hline
\end{tabular}

Table 2: Highest bids and auctioneers' decisions, per type of player.

\section{Dependent variable: $\operatorname{Bid}(t)$}

$\operatorname{Bid}(t-1)$

Likelihood

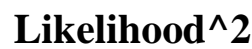

Likelihood*out

Likelihood^ $^{\wedge}$ *out

Fixed effects
(1) unbiased prior

$$
\begin{aligned}
& .0175(0.3) \\
& .8728(2.5)^{* *} \\
& -.0062(1.9)^{*} \\
& -.3367(1.5) \\
& .0037(1.0)
\end{aligned}
$$$$
\text { yes }
$$

896
order 2: 0.6795

Test $\mathbf{H}_{0}=$ zero autocorrelation $(\operatorname{Prob}>|\mathbf{z}|) \quad$ order $1: 0.0000 * * * \quad$ order $1: 0.0000 * * *$

(2) biased prior $.0288(0.5)$ $.8160(2.3) * *$ $-.0058(1.8) *$ $-.3219(1.1)$ $.0049(0.9)$ yes order 2: 0.6091

Notes: Absolute value $t$ in parenthesis. * significant 10\%; ** significant $5 \%$

Table 3: Players' reaction function. 